\title{
Study of safety and efficacy of injection ferric carboxymaltose in iron deficiency anemia in pregnancy
}

\author{
Amrita Jain', Sonia S. Asrani ${ }^{2 *}$ \\ Department of Obstetrics and Gynecology, GGMC and Sir J. J. Group of Hospitals, Mumbai, Maharashtra, India
}

Received: 28 March 2021

Accepted: 30 April 2021

*Correspondence:

Dr. Sonia S. Asrani,

E-mail: soniaasrani6@gmail.com

Copyright: $\odot$ the author(s), publisher and licensee Medip Academy. This is an open-access article distributed under the terms of the Creative Commons Attribution Non-Commercial License, which permits unrestricted non-commercial use, distribution, and reproduction in any medium, provided the original work is properly cited.

\section{ABSTRACT}

Background: Iron deficiency is a common nutritional deficiency amongst women of childbearing age. Peri-partum iron deficiency anemia (IDA) is associated with significant maternal, fetal and infant morbidity. Ferric carboxymaltose (FCM) may be better tolerated than the conventional blood transfusions and oral iron supplements. The study was designed to assess the safety and efficacy of IDA correction with intravenous (I.V.) FCM in pregnant women with mild, moderate and severe anemia in their second and third trimesters and their post-partum period. Methods: Prospective observational study; Treatment effectiveness was assessed by repeat hemoglobin ( $\mathrm{Hb})$ measurements and patient report of well-being in the postpartum period. Safety was assessed by analysis of adverse drug reactions and fetal heart rate monitoring during the infusion.

Results: Intravenous FCM infusion significantly increased $\mathrm{Hb}$ values above baseline levels in all women. Fetal heart rate monitoring did not indicate a drug related negative impact on the fetus. No serious adverse effects were found Conclusions: Our prospective data is consistent with existing observational reports of the safe and effective use of ferric carboxymaltose in the treatment of iron deficiency anemia in peri-partum period.

Keywords: Iron deficiency anemia, Ferric carboxymaltose, Safety, Effectiveness, Peri-partum

\section{INTRODUCTION}

Iron deficiency anemia (IDA) is a prevalent condition during pregnancy and may result from different factors.

During pregnancy, the physiological need for absorbed iron increases from $0.8 \mathrm{mg}$ /day in the first trimester to $7.5 \mathrm{mg} /$ day in the third trimester. ${ }^{1}$ Dietary iron intake does not compensate for this increased iron demand. Consequently, iron deficiency anemia sets in, which becomes evident by symptoms like lethargy, easy fatiguability, anorexia, etc. Anemia during pregnancy is associated with an increased risk of: Premature birth and low birth weight, Preeclampsia, Placental abruption, Increased peripartum blood loss, Cardiac failure and related death. ${ }^{2-7}$

In pregnant women, oral iron is often used for prophylaxis of iron deficiency and is recommended as first-line treatment for pregnant women with iron deficiency anemia. ${ }^{8}$ However, oral iron substitution has shown to be insufficient for the treatment of severe iron deficiency anemia and is often associated with gastrointestinal side effects. ${ }^{9}$ Therefore, physicians consider intravenous (I.V.) iron administration in pregnant women with iron deficiency anemia $(\mathrm{Hb}<9.0 \mathrm{~g} / \mathrm{dL})$. Ferric carboxymaltose (FCM) is an I.V. iron formulation which can be used at high doses and allows rapid administration (up to $1000 \mathrm{mg}$ in a single dose infused over 15-20 mins).

The aim of this prospective observational study was to assess the safety and efficacy of I.V. FCM in pregnancy.

\section{METHODS}

The inpatients of the department of OBGY at a tertiary care hospital, admitted in the period of June 2019 to May 
2020, were included in this prospective observational study. All women who received administration of Inj. FCM during their pregnancy and/or postpartum period were eligible for this study.

\section{Treatment characteristics}

Pregnant females with $\mathrm{Hb} \leq 9 \mathrm{gm} \%$ were counseled for Inj. FCM. The maximum weekly dose of $1000 \mathrm{mg}$ in a single infusion given over 15-20 minutes in $200 \mathrm{ml} \mathrm{NS}$. Total iron demand $(\mathrm{mg})=$ body weight $(\mathrm{kg}) \times$ (target $\mathrm{Hb}$ present $\mathrm{Hb}$ in $\mathrm{gm} / \mathrm{dL}) \times 2.4+500 \mathrm{mg}$.

\section{Outcome measures}

These were based on rise in Hb levels, adverse effects and pregnancy outcomes. $\mathrm{Hb}$ was rechecked after a period of 2 weeks to gauge the efficacy of FCM. Adverse effects could be hypersensitivity reaction during/after the infusion. Pregnancy outcomes like intrauterine growth retardation (IUGR), $\mathrm{Hb}$ at delivery, need for blood transfusion (BT), fetal weight, etc. were considered.

\section{RESULTS}

56 women who received injection FCM in the course of 12 months at our hospital were included in this study, of which 18 women received Inj. FCM post-partum. Demographic characteristics such as age, gravida, antenatal/postnatal period, gestational age, $\mathrm{Hb}$ on admission, Sr. Ferritin levels on admission, rise in $\mathrm{Hb}$ after FCM infusion \& perinatal outcomes were studied. 8 of the total number of patients included in this study required blood transfusion in addition to FCM infusion, owing to severe IDA in their cases.

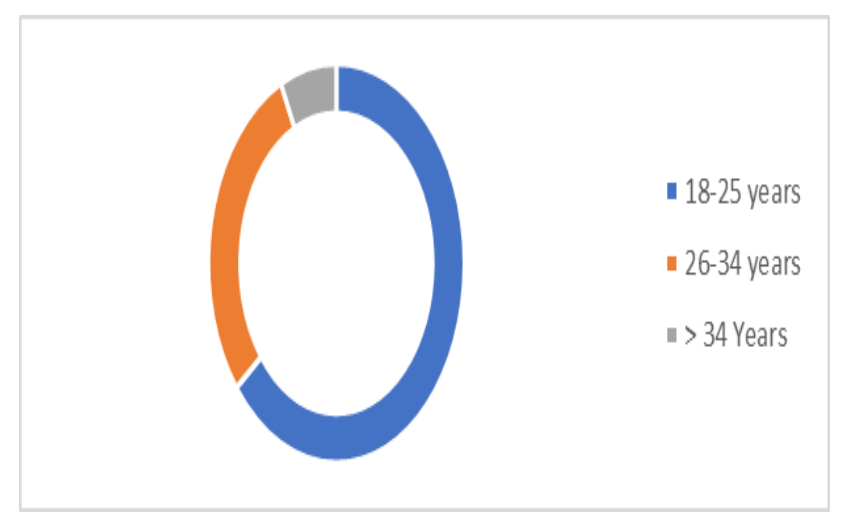

Figure 1: Age distribution of participants in this study.

Amongst the total 56 patients, 36 were in the age group of 18-25 years, 16 in the age group of 26-34 years, and 4 were above 34 years.

Of the 38 women who received inj. FCM in their antenatal period, 4 were primigravidae, and the rest were multigravidas.

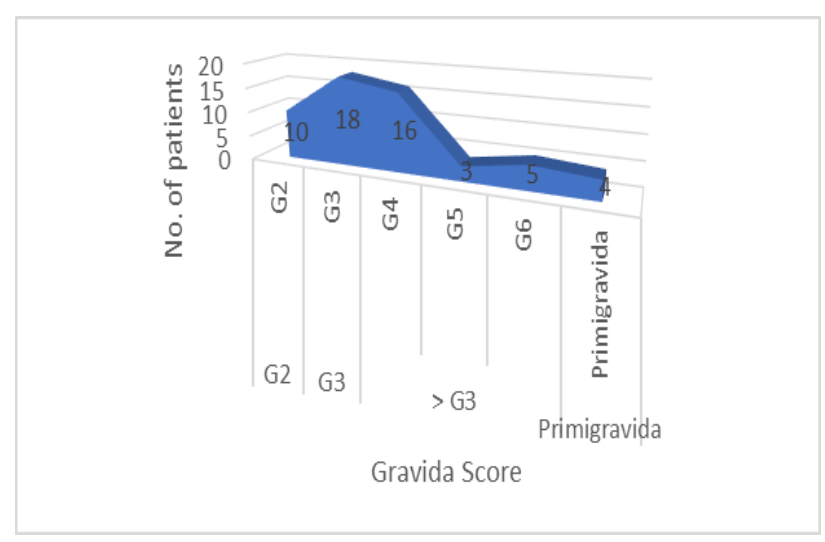

Figure 2: Gravida scores of the participants.

The average hemoglobin of primigravidae on admission was $8.83 \mathrm{gm} / \mathrm{dl}$, and the situation worsened with increase in gravida score in multigravidas, with the lowest average hemoglobin of $6.44 \mathrm{gm} / \mathrm{dl}$.

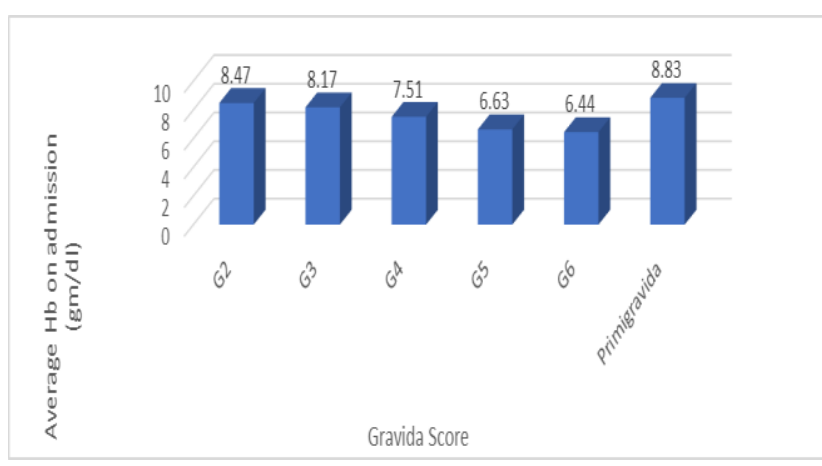

Figure 3: Association between gravida score and anemia.

The number of patients with hemoglobin of less than 8 $\mathrm{gm} / \mathrm{dl}$ on admission, was 32 , and those with hemoglobin ranging between $8 \mathrm{gm} / \mathrm{dl}$ and $9 \mathrm{gm} / \mathrm{dl}$ were 24 .

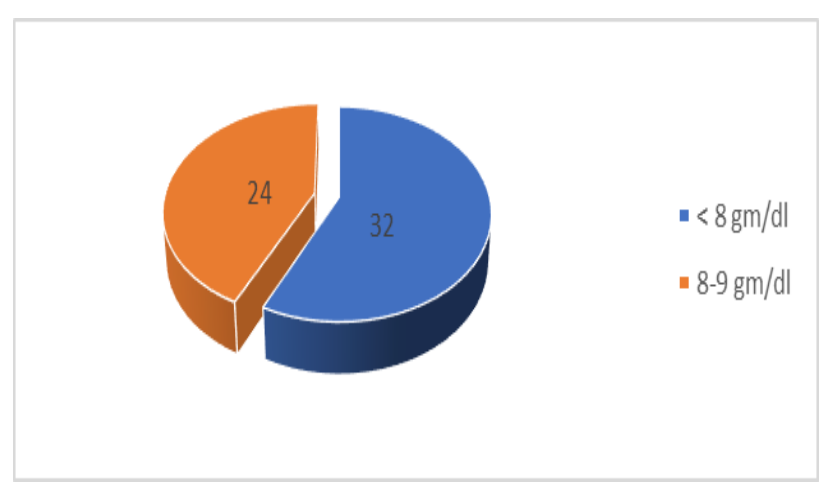

Figure 4: Hemoglobin levels on admission.

With respect to the Sr. ferritin levels on admission, 24 women fell in the range of $21-30 \mathrm{ng} / \mathrm{ml}$, and 18 in the range of $10-20 \mathrm{ng} / \mathrm{ml}$. 14 women had their Sr. ferritin levels below $10 \mathrm{ng} / \mathrm{ml}$. 


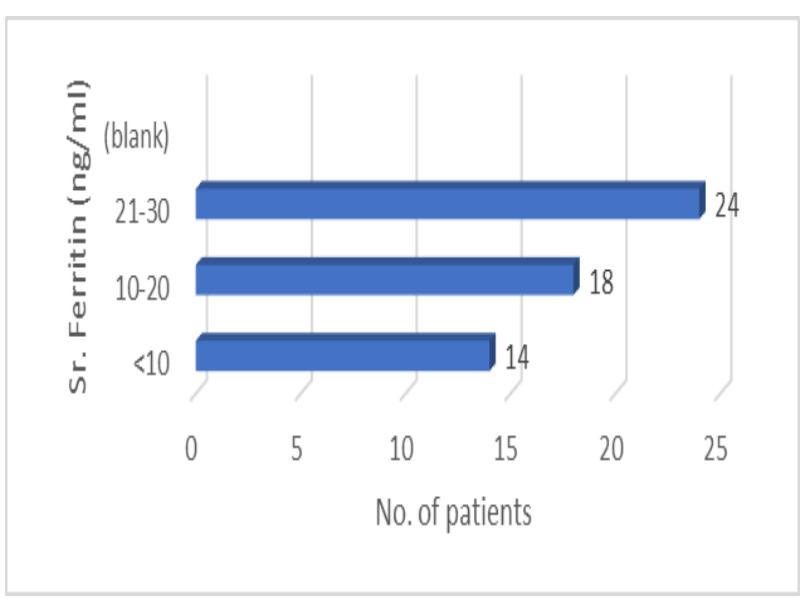

Figure 5: Sr. Ferritin levels of the study group.

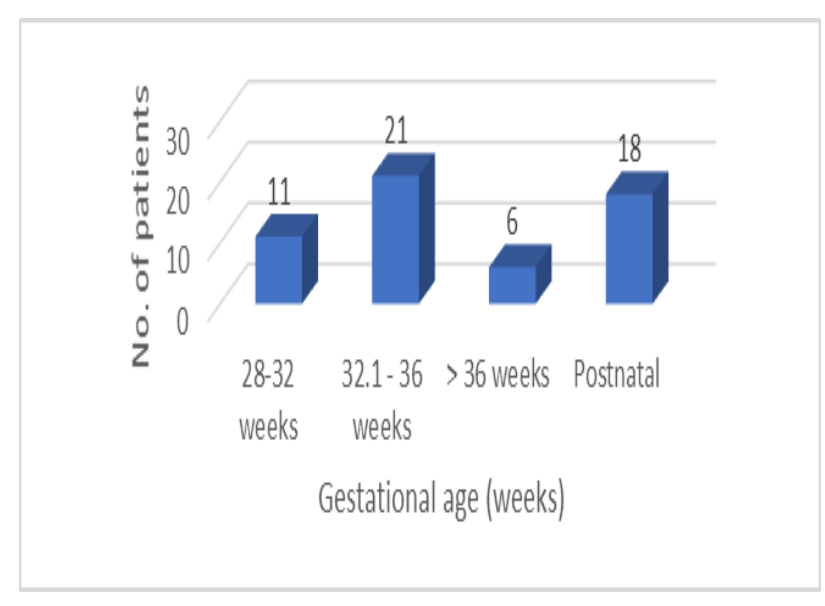

Figure 6: Gestational age at the time of FCM infusion.

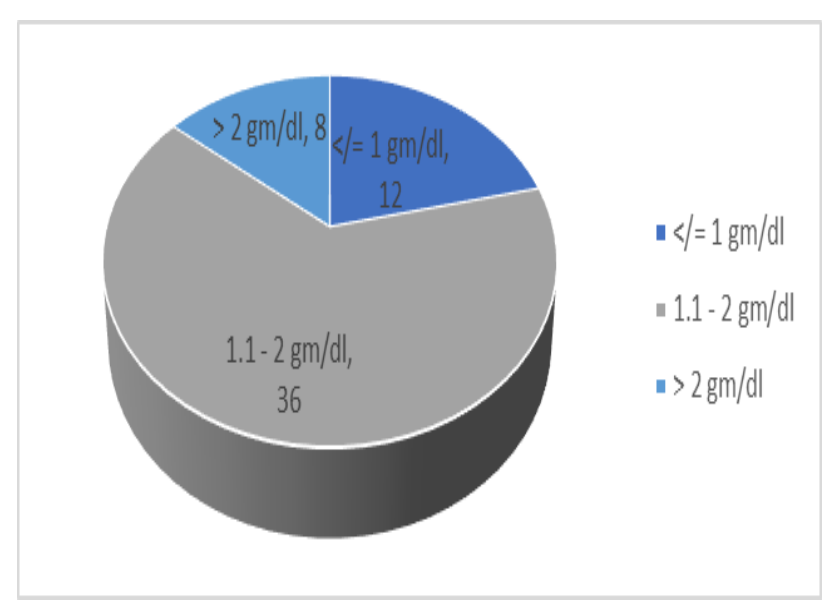

Figure 7: Rise in hemoglobin levels post FCM infusion.

Those who were administered injection FCM at the gestational age of $28-32$ weeks were 11 in number. 21 patients were given FCM infusion at the gestational age of 32.1 weeks to 36 weeks, and 6 patients received it beyond the gestational age of 36 weeks. 18 of the total patients included in this study were given FCM infusion in their post-natal period.
The rise of hemoglobin observed post injection FCM infusion was up to $2.5 \mathrm{gm} / \mathrm{dl}$. 8 women had a rise of more than $2 \mathrm{gm} / \mathrm{dl}$, 36 women had a rise of 1.1 to $2 \mathrm{gm} / \mathrm{dl}$ and the rest $12 \mathrm{had}$ an increment of less than $1 \mathrm{gm} / \mathrm{dl}$ in their hemoglobin levels.

\section{DISCUSSION}

This observational study investigated the efficacy and safety of FCM in IDA during peri partum period. FCM treatment efficiently increased $\mathrm{Hb}$ both in pregnancy and post-partum period. Mean gestational age at the time of FCM infusion was 33.4 weeks (Figure 6). Mean increase in $\mathrm{Hb}$ was from $7.8 \mathrm{gm} / \mathrm{dl}$ to $9.2 \mathrm{gm} / \mathrm{dl}$ (a mean increment of $1.4 \mathrm{gm} / \mathrm{dl}$ ) (Figure 7). No treatment-related adverse events were observed. All patients had uneventful course post FCM infusion.

Blood transfusion is not only a costly affair but also short in supply and has its share of well-defined risks and adverse effects. In cases with mild to moderate IDA associated with pregnancy and post-partum period, FCM infusion can help avoid the need for blood transfusion. However, in this study, blood transfusion, over and above FCM infusion, was required in 8 of the total 56 patients, due to severe anemia.

Our study showcases the safety and efficacy of FCM infusion in treating IDA in peri-partum period, while simultaneously aiming at bypassing the need for blood transfusion. The number of patients opting for inj FCM however has been limited in our setup, owing to the affordability issues and non-availability of FCM at our tertiary care hospital. This explains the small sample size of our study.

There are various problems associated with oral iron preparations, like gastrointestinal side effects, intolerability to oral iron, non-compliance of patients, etc. In such cases injection FCM comes to the rescue, as it is devoid of all such short comings.

There are numerous studies which have documented the efficacy and safety of FCM treatment in IDA associated with pregnancy. In one study with 457 patients, after 6 weeks of FCM infusion, rise in Hb level by $\geq 2 \mathrm{~g} / \mathrm{dl}$ was attained by $41 \%$ of all the patients. Hb increase of $\geq 3 \mathrm{~g} / \mathrm{dl}$ after 6 weeks after FCM dose was attained by $20 \%$ of all patients. ${ }^{10}$ Two retrospective studies mentioned the efficacy and safety profile of FCM in pregnant women with IDA. ${ }^{11,12}$ In these studies FCM was administered in second and third trimesters with an increase in mean haemoglobin values from $8.4 \mathrm{~g} / \mathrm{dl}$ to $11 \mathrm{~g} / \mathrm{dl}$. No adverse events related with treatment and no adverse obstetric outcomes were reported. Sharma et al reported an increase of $3.14 \mathrm{~g} / \mathrm{dl}$ in mean haemoglobin values 14 days after they treated postpartum anaemia with FCM infusion. ${ }^{13}$ In one systematic review, FCM when compared to other iron formulation, performed better in the achievement of a rapid and consistent $\mathrm{Hb}$ response. ${ }^{14}$ 


\section{CONCLUSION}

FCM treatment efficiently increased $\mathrm{Hb}$ from baseline in cases of mild to moderate IDA in peri-partum period, while avoiding the need for blood transfusion. There were no hypersensitivity reactions, anaphylactic reactions, or other adverse events with respect to the mother's or the baby's health reported with FCM treatment. In fact, maternal and fetal outcomes were also improved. Treatment of IDA by FCM infusion must therefore be considered in pregnancy and post-partum period to avoid transfusing blood as much as possible.

\section{ACKNOWLEDGMENTS}

Funding: No funding sources Conflict of interest: None declared

Ethical approval: The study was approved by the Institutional Ethics Committee

\section{REFERENCES}

1. Milman N, Bergholt T, Byg KE, Eriksen L, Graudal $\mathrm{N}$. Iron status and iron balance during pregnancy. A critical reappraisal of iron supplementation. Acta Obstetricia et Gynecologica Scandinavica. 1999;78(9):749-57.

2. Scholl TO. Iron status during pregnancy: setting the stage for mother and infant. Am $\mathbf{J}$ Clin Nutr. 2005;81(5):1218s-22.

3. Milman N, Agger O, Nielsen OJ. Iron status markers and serum erythropoietin in 120 mothers and newborn infants. Effect of iron supplementation in normal pregnancy. Acta Obstetricia et Gynecologica Scandinavica. 1994;73(3):200-4.

4. Arnold DL, Miller RS, Qiu C, Sorensen TK. Iron deficiency anemia, cigarette smoking and risk of abruptio placentae. J Obstetr Gynaecol Res. 2009;35(3):446-52.

5. Reveiz L, Gyte GM, Cuervo LG, Casasbuenas A. Treatments for iron-deficiency anaemia in pregnancy. Cochrane Database Systematic Rev. $2001 ; 10$.

6. Viteri FE. The consequences of iron deficiency and anaemia in pregnancy on maternal health, the foetus and the infant. SCN News. 1994;11:14-8.
7. Villar J, Merialdi M, Gülmezoglu AM. Nutritional interventions during pregnancy for the prevention or treatment of maternal morbidity and preterm delivery: an overview of randomized controlled trials. J Nutr. 2003;133(5):1606s-25.

8. Breymann C, Honegger C, Holzgreve W, Surbek D. Diagnosis and treatment of iron-deficiency anaemia during pregnancy and postpartum. Arch Gynecol Obste. 2010;282(5):577-580.

9. Milman N. Prepartum anaemia: prevention and treatment. Ann Hematol. 2008;87(12):949-59.

10. Nunes AR, Costa AP, Rocha SL. efficacy and Tolerability of Intravenous Ferric Carboxymaltose in Patients with Iron Deficiency at a Hospital Outpatient Clinic: A Retrospective Cohort Study of Real-World Clinical Practice. Anemia. 2017:1-7.

11. Rodriguez RA, Montero MG, Lorente Aporta JP. Clinical Study Retrospective Case Reports of Anemic Pregnant Women Receiving Intravenous Ferric Carboxymaltose: Experience from a Tertiary Hospital in Spain. Obstet Gynecol Int. 2016;2016:5060252.

12. Pels A, Ganzevoort WJ. Safety and Efficacy of Ferric Carboxymaltose in Anemic Pregnant Women: A Retrospective Case Control Study. Obstet Gynecol Int. 2015;2015:728952.

13. Bisbe E, Garcia-Erce JA, Diez-Lodo AI. A multicentre comparative study on the efficacy of intravenous ferric carboxymaltose and iron sucrose for correcting preoperative anaemia in patients undergoing major elective surgery. $\mathrm{Br} \mathrm{J}$ Anaesth. 2011;107(3):477-8.

14. Rognoni C, Venturini S, Meregaglia M. Efficacy and Safety of Ferric Carboxymaltose and Other Formulations in Iron-Deficient Patients: A Systematic Review and Network Meta-analysis of Randomised Controlled Trials. Clin Drug Investig. 2016;36(3):177-94.

Cite this article as: Jain A, Asrani SS. Study of safety and efficacy of injection ferric carboxymaltose in iron deficiency anemia in pregnancy. Int J Reprod Contracept Obstet Gynecol 2021;10:2298-301 